\title{
Some Ions of Hexamethylene Triperoxide Diamine - A DFT Treatment
}

\section{Lemi Türker}

Department of Chemistry, Middle East Technical University, Üniversiteler, Eskişehir Yolu No: 1, 06800 Çankaya/Ankara, Turkey; e-mail: 1turker@gmail.com; lturker@metu.edu.tr

\begin{abstract}
Hexamethylene triperoxide diamine (HMTD) is one of the peroxide type organic explosive which is sensitive to various stimuli including electrical charging. In the present study, within the restrictions of density functional theory at the level of B3LYP/6$311++\mathrm{G}(\mathrm{d}, \mathrm{p})$ some ionic forms of HMTD have been investigated. Its anionic and cationic forms considered all undergo decomposition. The monoanion form exhibited cleavage of two peroxide bonds and two $\mathrm{C}-\mathrm{H}$ bonds whereas the monocation and dication forms show the rupture of $\mathrm{O}-\mathrm{CH}_{2}$ bonds. Some quantum chemical properties and UV-VIS spectra of HMTD and the decomposed products were obtained and discussed.
\end{abstract}

\section{Introduction}

HMTD was discovered in 1885 by Legler using formaldehyde, ammonium sulfate, and hydrogen peroxide [1]. The structure was proposed in 1900 by Baeyer and Villiger [2]. Von Girsewald was the first to use hexamine, citric acid, and hydrogen peroxide to synthesize it [3]. The ring strain in HMTD may account for its low thermal stability and high sensitivity to friction [4,5]. Since HMTD is an extremely sensitive primary explosive; one has to avoid using any fritted glass, metal spatulas or excess force or friction [6]. Since HMTD is destabilized by water and citric acid, it is important to purify it after initial synthesis. Ignoring the degrading effects of water and acid may lead to an unexpected violent reaction during storage and handling [6]. Oxley et al., studied the synthesis and decomposition of hexamethylene triperoxide diamine (HMTD). They proposed some mechanisms based on isotopic labeling and mass spectral interpretation of

Received: February 2, 2022; Accepted: February 26, 2022

Keywords and phrases: hexamethylene triperoxide diamine; HMTD; peroxide explosives; explosives; density functional theory.

Copyright (C) 2022 Lemi Türker. This is an open access article distributed under the Creative Commons Attribution License (http://creativecommons.org/licenses/by/4.0/), which permits unrestricted use, distribution, and reproduction in any medium, provided the original work is properly cited. 
both condensed phase products and head-space products [6]. Matyas, Selesovsky, and Musil, worked on decreasing the friction sensitivity of TATP, DADP, and HMTD [5]. Schaefer, Fourkas, and Tiemann, also contributed the structure of hexamethylene triperoxide diamine [7]. Wierzbicki et al., performed some density functional calculations and X-ray investigations on $\mathrm{P}$ - and $\mathrm{M}$-hexamethylene triperoxide diamine and its dialdehyde derivative [8]. Oxley and coworkers investigated decomposition, some reactions and some properties of HMTD [9-13]. Aernecke et al., developed a rapid method for vapor pressure measurement and used to derive the vapor pressure curve of the thermally labile peroxide-based explosive hexamethylene triperoxide diamine (HMTD) [14]. The spark sensitivity of HMTD was measured and found to be comparable to TATP [15].

In the present study, some ions of HMTD have been considered within the restrictions of density functional theory (DFT) at the level of UB3LYP/6-311++/G(d,p). Note that spark sensitivity should be an implicit function of ionic form of certain species that they eventually should form exposed to spark.

\section{Method of Calculations}

Initially all the structures were subjected to MM2 geometry optimizations leading to energy minima followed by semi-empirical PM3 self-consistent fields molecular orbital (SCF MO) method [16,17] at the restricted level [18]. Then, the structure optimizations have been achieved within the framework of Hartree-Fock (HF) and finally by using density functional theory (DFT) at the level of UB3LYP/6-311++G(d,p) [19,20]. The exchange term of B3LYP consists of hybrid Hartree-Fock and local spin density (LSD) exchange functions with Becke's gradient correlation to LSD exchange [21]. It is worth mentioning that the correlation term of B3LYP consists of the Vosko, Wilk, Nusair (VWN3) local correlation functional [22] and Lee, Yang, Parr (LYP) correlation correction functional [23]. The normal mode analysis for each structure presently considered yielded no imaginary frequencies for the $3 N-6$ vibrational degrees of freedom. Note that $N$ is the number of atoms in the system and the present normal mode analysis indicates that the structure of each molecule corresponds to at least a local minimum on the potential energy surface. Furthermore, all the bond lengths were thoroughly searched in order to find out whether any bond cleavage occurred or not during the geometry optimization process. A rather high-level basis set has been employed in order to minimize the effect of basis set superposition error (BSSE) which 
accompanies in the case of open-shell systems. All these computations were performed by using SPARTAN 06 [24].

\section{Results and Discussion}

The structure of HMTD is shown below. The ring strain present and caused by peroxide linkages in HMTD may account for its highly sensitive nature to many stimuli and its low thermal stability [4,5]. When dealing with organic peroxides, the relative strengths of the $\mathrm{O}-\mathrm{O}$ bond are of vital importance, both from a safety and mechanistic perspective. It is well known that such oxidizing agents are highly reactive and reliable $\mathrm{O}-\mathrm{O}$ bond dissociation energies (BDEs) have only recently been established by Bach and Schlegel employing computational methods [25]. A median O-O BDE value of ca. 45 $\mathrm{kcal} / \mathrm{mol}$ was obtained for a variety of well-known peroxides [25].

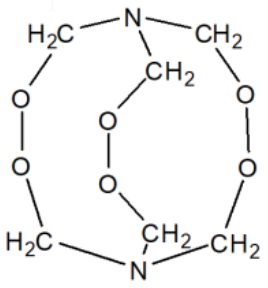

\section{HMTD}

Figure 1 shows the optimized structures of HMTD and its ions presently considered, as well as the direction of the dipole moment vectors of them (see also Table 1). In the present study the monoanion and monocation have doublet multiplicity, whereas dications are either in singlet or triplet state. Note that those structures shown and labeled in Figure 1 are actually decomposition products of the ions considered although in the text below most of the time they are named as the name of the parent ion(s). In Figure 1, the states have been indicated in parenthesis as (s), (d) or (t). As seen in Table 1 the decomposition products of the charged species possess dipole moments highly variable as a consequence of structure optimization, thus the charge distribution (Table 1).

Table 1. Dipole moments of the species presently concerned.

\begin{tabular}{ccccc}
\hline HMTD & Monoanion(d) & Monocation(d) & Dication(s) & Dication(t) \\
\hline 0.09 & 10.00 & 3.33 & 2.75 & 0.57 \\
\hline
\end{tabular}

In Debye units. 


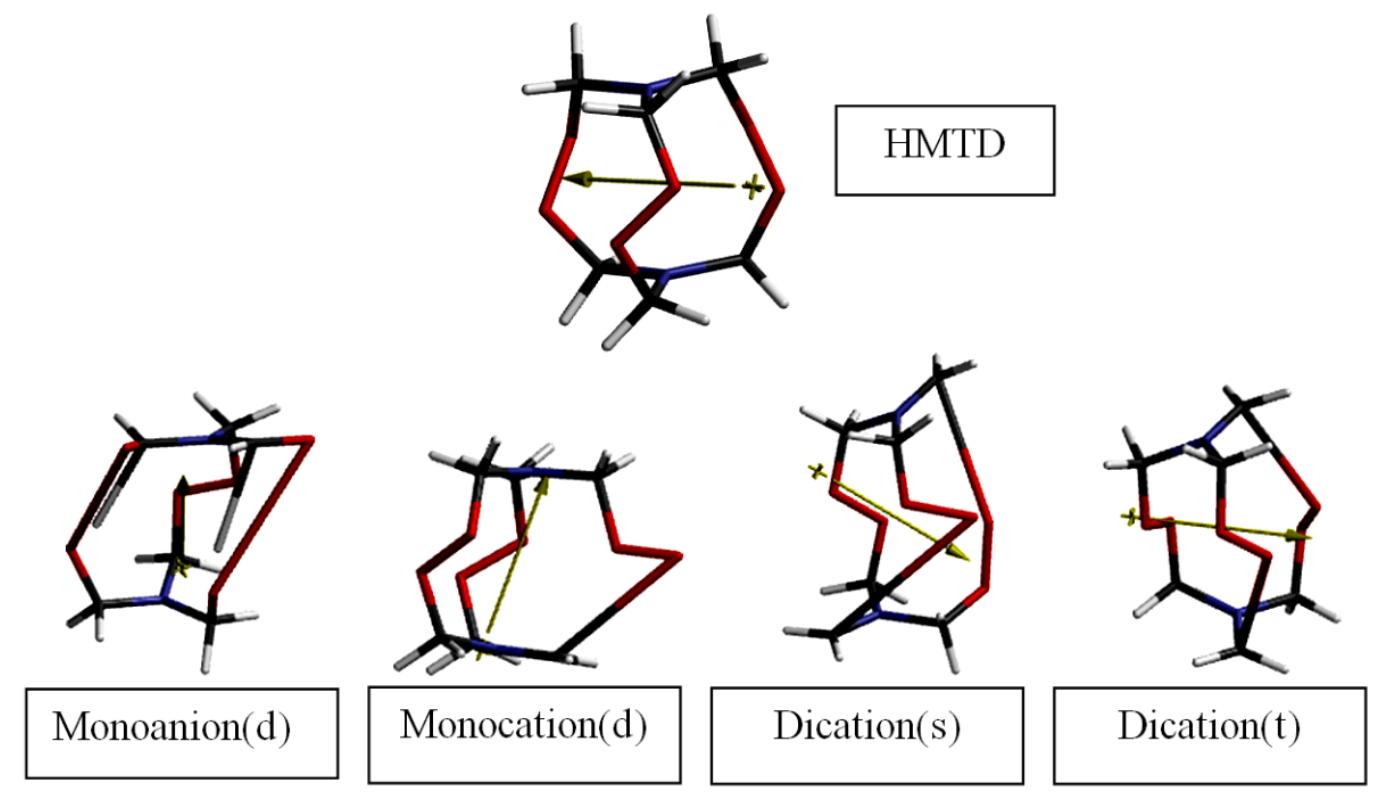

Figure 1. Optimized structures of HMTD and decomposition products of its ions considered.

As seen in the figure all the ions have been considered are sensitive to ionization however their cleavage patters are different. In the monoanion case, not only the peroxide bonds rupture but also two of the $\mathrm{C}-\mathrm{H}$ bonds undergo bond rupture. The $\mathrm{C}-\mathrm{H}$ distances of those are 2.237 and $2.621 \AA$. The length of peroxide linkages are 3.727 and $3.989 \AA$. One of the three peroxide bonds remains intact having the bond length of $1.475 \AA$. The $\mathrm{N}-\mathrm{CH}_{2}$ bond lengths are variable in between 1.37-1.46 $\AA$.

The monocation keeps the integrity of the peroxide bonds, two of them have the bond length of $1.466 \AA$ whereas the third has $1.313 \AA$ which is linked to the broken $\mathrm{O}-\mathrm{CH}_{2}$ moiety. The $\mathrm{N}-\mathrm{CH}_{2}$ bonds vary in between $140-1.43 \AA$ and $1.28-1.50 \AA$. In the second set, $\mathrm{N}-\mathrm{CH}_{2}$ bond of $1.28 \AA$ length has been linked to the broken $\mathrm{O}-\mathrm{CH}_{2}$.

The dication in the singlet state has the peroxide bonds of 1.47-1.55 $\AA$. Of the three peroxide bonds of the HMTD, two of them exhibit bond rupture. The intact peroxide bond has $\mathrm{O}-\mathrm{CH}_{2}$ bonds of $1.38 \AA$. Whereas, two of the $\mathrm{O}-\mathrm{CH}_{2}$ bonds which undergo bond cleavage have $\mathrm{O}-\mathrm{CH}_{2}$ distance of 3.41 and $4.19 \AA$ and $\mathrm{CH}_{2}$ group in each case linked to different nitrogen atoms. On the other hand, the $\mathrm{N}-\mathrm{CH}_{2}$ bond vary between 1.27-1.55 $\AA$. The $\mathrm{N}-\mathrm{CH}_{2}$ bond linked to the broken $\mathrm{O}-\mathrm{CH}_{2}$ (in each case of nitrogen) is characterized with the shortest bond length (1.27 $\AA$ ). 
For the dication there exists another possibility in terms of multiplicity that is the triplet case. As seen in Figure 1, in this case also two of the $\mathrm{O}-\mathrm{CH}_{2}$ bonds underwent bond cleavage having distances of 2.91 and $2.93 \AA$ between the termini of the broken bonds. The peroxide bonds linked to those broken $\mathrm{O}-\mathrm{CH}_{2}$ bonds have the bond length of $1.31 \AA$ whereas the intact peroxide bond is $1.47 \AA$. The $\mathrm{N}-\mathrm{CH}_{2}$ bonds vary in between 1.28-1.51 $\AA$ in both sets of the $\mathrm{N}-\mathrm{CH}_{2}$ linkages in the molecule. The shortest of them in each set belongs to $\mathrm{N}-\mathrm{CH}_{2}$ bond also linked to the broken $\mathrm{O}-\mathrm{CH}_{2}$ bond.

Figure 2 shows the electrostatic potential field (ESP) charges on the atoms of HMTD and the decomposition products of its ions considered. Note that the ESP charges are obtained by the program based on a numerical method that generates charges that reproduce the electrostatic potential field from the entire wavefunction [24]. In the case of monoanion, as seen in Figure 1, two of $\mathrm{C}-\mathrm{H}$ bonds from different $\mathrm{CH}_{2}$ groups but linked to the same nitrogen atom undergo bond cleavage. The hydrogens of those broken bonds possess positive charges ( 0.460 and $0.477 \mathrm{esu}$ ). All the oxygens have negative charges whereas some of the carbons are positive and some negatively charged. The nitrogen atom linked to $\mathrm{CH}_{2}$ groups having the broken $\mathrm{C}-\mathrm{H}$ bond is positively but the other nitrogen negatively charged in the anion.

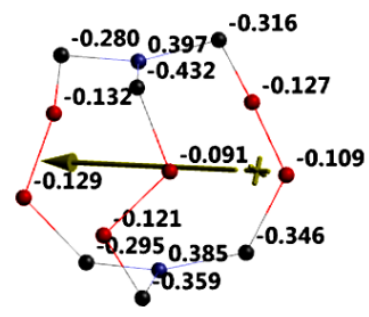

HMTD
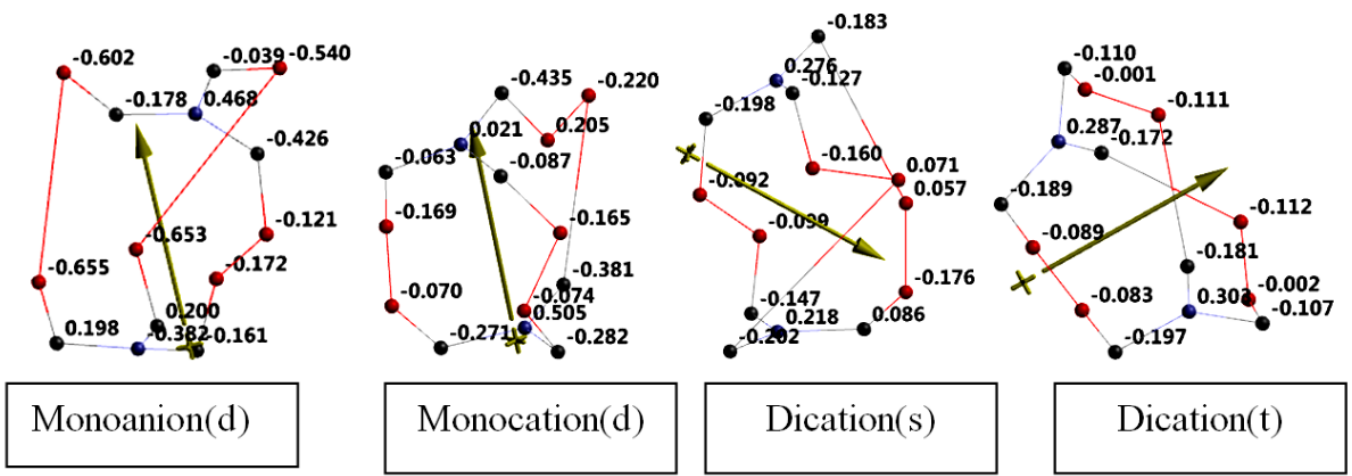

Figure 2. The electrostatic potential field charges on the atoms of HMTD and its decomposition products considered (Hydrogens omitted). 
In the case of the monocation products, all the peroxide oxygens, except the one are negatively charged. Both of the nitrogen atoms acquire positive charges but highly different from each other in magnitude. The carbons are all negative.

The dication singlet possess one intact peroxide bond having negatively charged oxygen atoms. The oxygen atoms of the other peroxide bonds having broken $\mathrm{O}-\mathrm{CH}_{2}$ bond are positively charged but the carbons at those loci possess positive charge. All the carbon atoms except one possess negative charges and both of the nitrogens acquire some positive partial charges. As for the triplet dication, all the oxygens are negatively charged but peroxide oxygens of the broken $\mathrm{O}-\mathrm{CH}_{2}$ bonds have greater charges then their partner oxygen atoms. Moreover, atoms at the termini of the broken bonds $\left(\mathrm{O}-\mathrm{CH}_{2}\right)$ have negative charges implying homolytic bond cleavage of perturbed type. The triplet dication like the singlet case has positively charged nitrogen atoms. All the carbons, in contrast to the singlet form are negatively charged. The ionic species considered all decompose on charging but exhibit different patterns. In the anion case, two of the peroxide linkages but in the monocation and dication cases one and two $\mathrm{O}-\mathrm{CH}_{2}$ bonds undergo bond cleavages, respectively but the peroxide bonds remain intact. When excess charge(s) loaded on HMTD molecule it is distributed over the molecular system in such a way that energy minimization during the structure optimization occurs by the rupture of some suitable bonds.

Table 2 shows the total electronic energy (E), zero point energy (ZPE) and the corrected total electronic energies of the species shown in Figure 1. Note that the species labeled as dication(t) is electronically less stable than dication(s) because not only their spin states differ but also they are structurally different.

Table 2. Some energies of the species considered.

\begin{tabular}{cccc}
\hline Structure & $\mathbf{E}$ & $\mathbf{Z P E}$ & $\mathbf{E}_{\mathbf{C}}$ \\
\hline HMTD & -2091561.10 & 545.12 & -2091015.98 \\
Monoanion(d) & -2092148.65 & 524.35 & -2091624.30 \\
Monocation(d) & -2090775.99 & 538.52 & -2090237.47 \\
Dication(s) & -2089613.52 & 531.38 & -2089082.14 \\
Dication(t) & -2089591.31 & 530.10 & -2089061.21 \\
\hline
\end{tabular}

Energies in $\mathrm{kJ} / \mathrm{mol}$. 
Some of the molecular orbital energies of HMTD and the charged species considered are shown in Figure 3. Note that in the case of open-shell systems $\alpha$ - and $\beta$-type orbitals exist. In the figure they are shown as a- and b-types, respectively.
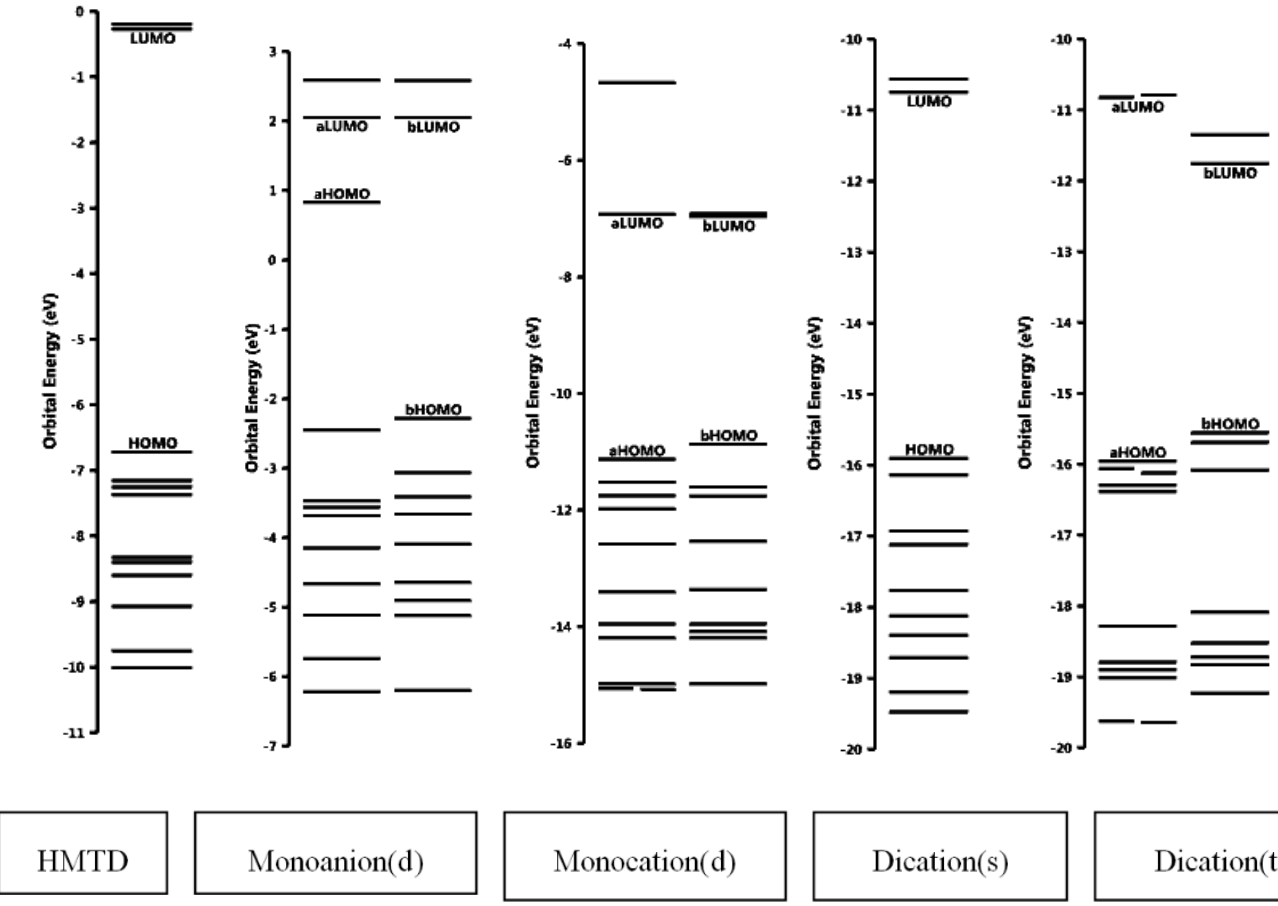

Dication(t)

Figure 3. Some of the molecular orbital energies of the charged species considered.

Table 3 shows the HOMO, LUMO energies and $\Delta \varepsilon$ values $\left(\Delta \varepsilon=\varepsilon_{\text {LUMO }}-\varepsilon_{\text {HOMO }}\right)$ of the species considered. As seen in the table negative charge accumulation on HMTD

Table 3. The HOMO, LUMO energies and $\Delta \varepsilon$ values of the species considered.

\begin{tabular}{cccc}
\hline Structure & HOMO & LUMO & $\boldsymbol{\Delta} \boldsymbol{\varepsilon}$ \\
\hline HMTD & -648.33 & -26.30 & 622.03 \\
Monoanion(d) & 79.83 & 197.97 & 118.14 \\
Monocation(d) & -1073.73 & -667.92 & 405.81 \\
Dication(s) & -1534.14 & -1037.09 & 497.05 \\
Dication(t) & -1539.52 & -1044.36 & 495.16 \\
\hline
\end{tabular}

Energies in $\mathrm{kJ} / \mathrm{mol}$. 
molecule yields a decomposition product having highly elevated HOMO and LUMO levels as compared to the parent compound. The cations formed have a converse effect on the frontier molecular orbitals. As for the interfrontier molecular orbital energy gap values $(\Delta \varepsilon)$ the order is HMTD $>\operatorname{Dication}(\mathrm{s})>\operatorname{Dication}(\mathrm{t})>\operatorname{Monocation}(\mathrm{d})>$ Monoanion(d).

Figure 4 displays time-dependent density functional (TDDFT) UV-VIS spectra of the species considered. As seen in the spectra, HMTD has a smooth envelop type spectrum whereas charged-decomposed products exhibit very different patterns over the whole region somewhat in accord with $\Delta \varepsilon$ values listed in Table 3.
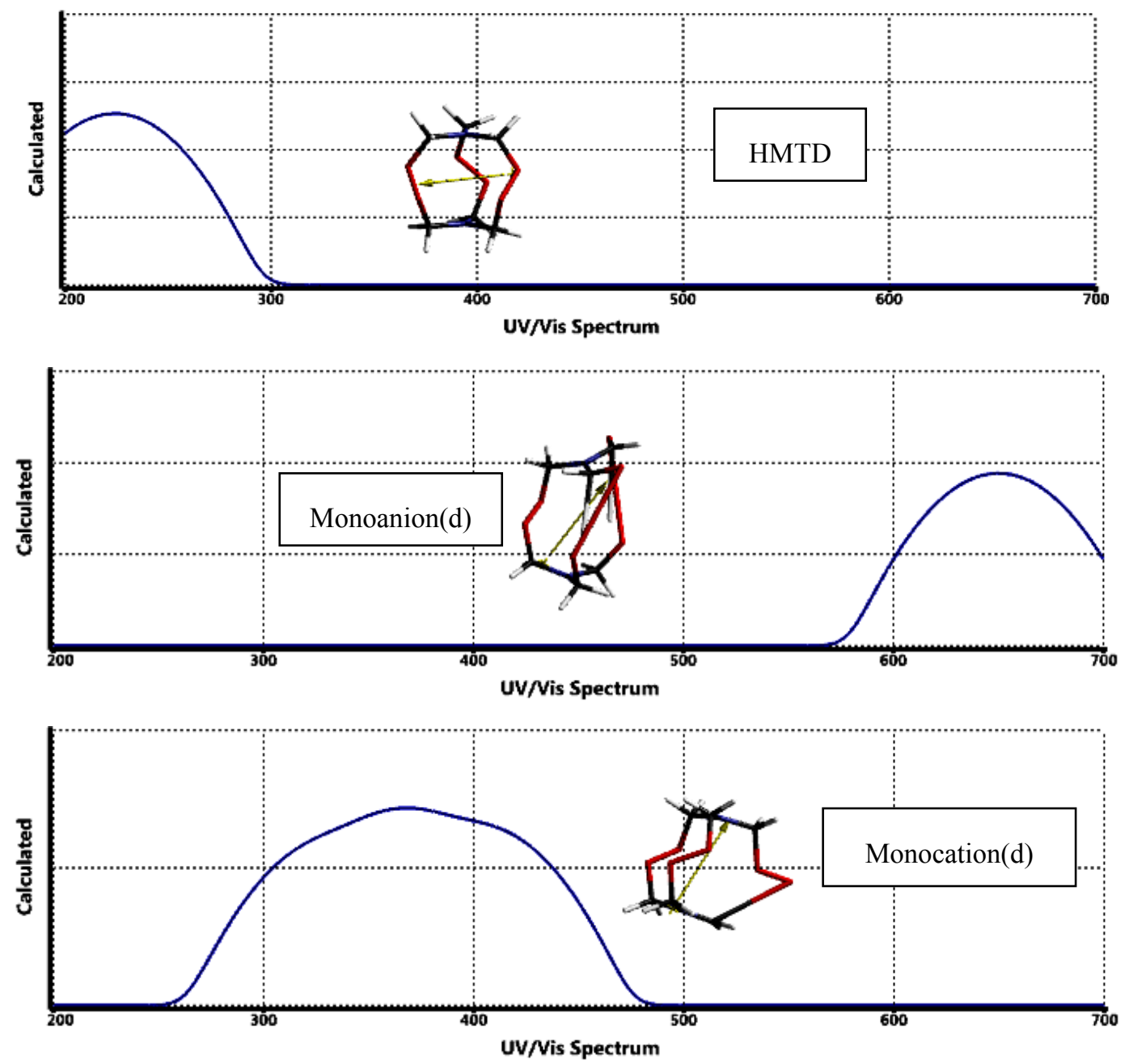

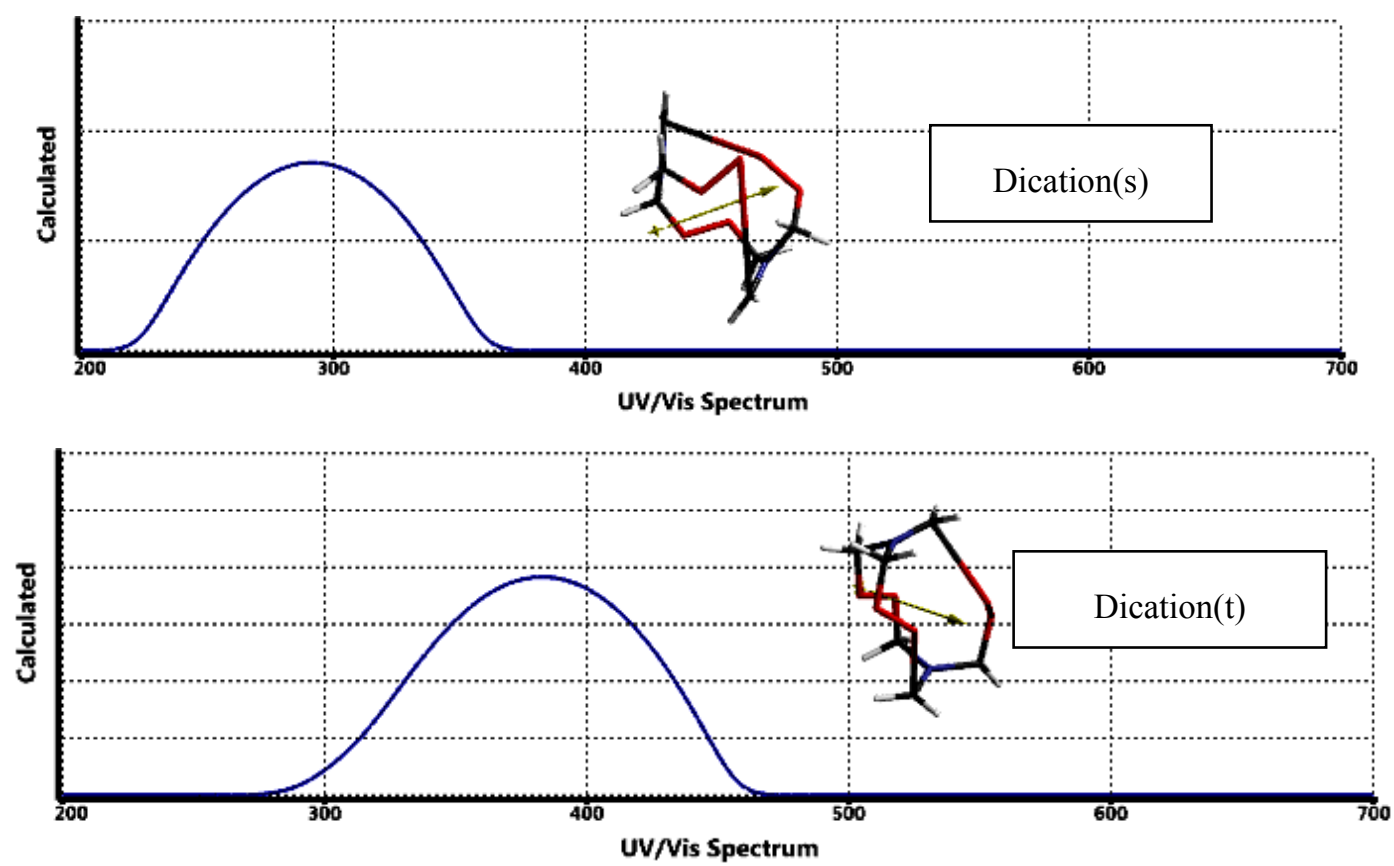

Figure 4. Time-dependent density functional UV-VIS spectra of the species considered.

Figure 5 shows the spin densities of the opened-shell species of the present concern. In the anion case the spin density accumulates around the broken peroxide bond oxygens (unequally partitioned) and their $\mathrm{CH}_{2}$ neighbors which possess the broken $\mathrm{C}-\mathrm{H}$ bond. In the monocation case the density spreads over the peroxide bond which is flanked by the broken $\mathrm{O}-\mathrm{CH}_{2}$ bond.
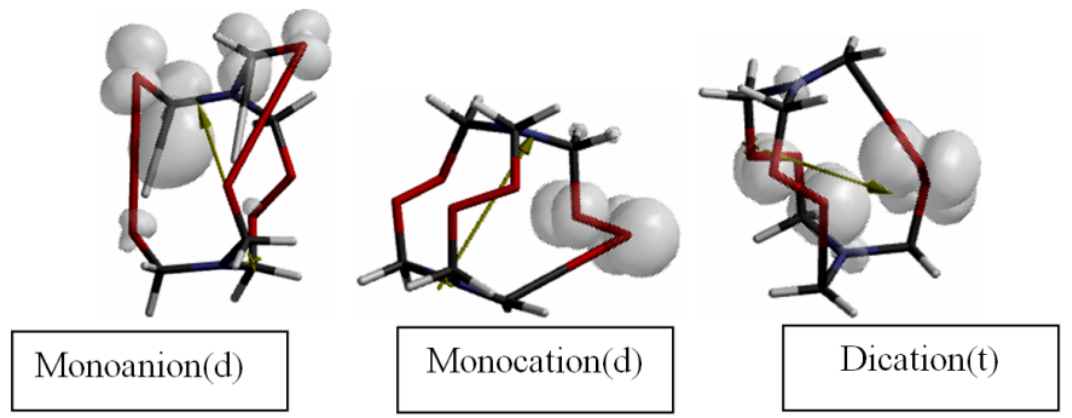

Figure 5. Spin densities of the opened-shell ions of the present concern.

\section{Conclusion}

The present study, within the constraints of the theory and the basis set presently 
employed shows that all the ionic forms of HMTD decompose by electrical charging displaying different patterns of decomposition. The monoanion form exhibited cleavage of two peroxide bonds and two $\mathrm{C}-\mathrm{H}$ bonds originating from two different $\mathrm{CH}_{2}$ moieties linked to the same nitrogen atom whereas the monocation and dication forms show the rupture of $\mathrm{O}-\mathrm{CH}_{2}$ bonds which linked to the different nitrogen atoms of HMTD structure. The UV-VIS spectrums of HMTD and monoanion product absorb in UV and visible regions, respectively. The monocation product absorbs partly in the ultraviolet and partly in the visible regions of the spectrum. The dication decomposed form absorbs in the ultraviolet in the singlet case but somewhat shifts to the visible side in the triplet case.

\section{References}

[1] Legler, L. (1885). Ueber Produkte der langsamen Verbrennung des Aethylethers. Ber. Dtsch. Chem. Ges., 18(2), 3343-3351. https://doi.org/10.1002/cber.188501802306

[2] Baeyer, A., \& Villiger, V. (1900). Über die Nomenclatur der Superoxyde und die Superoxyde der Aldehyde. Ber. Dtsch. Chem. Ges., 33(2), 2479-2487.

[3] Girsewald, C. (1912). Beiträge zur Kenntnis des Wasserstoffperoxyds. Über die Einwirkung des Wasserstoffperoxyds auf Hexamethylentetramin. Ber. Dtsch. Chem. Ges., 45, 2571-2576. https://doi.org/10.1002/cber.191204502161

[4] Oxley, J.C., Smith, J.L., Bowden, P., \& Rettinger, R. (2013). Factors influencing TATP and DADP formation: Part I. Propellants Explos. Pyrotech., 38, 244-254. https://doi.org/10.1002/prep.201200116

[5] Matyas, R., Selesovsky, J., \& Musil, T. (2013). Decreasing the friction sensitivity of TATP, DADP, and HMTD. Cent. Eur. J. Energ. Mater., 10(2), 263-275.

[6] Oxley, J.C., Smith, J.L., Porter, M., McLennan, L., Colizza, K., Zeiri, Y., Kosloff, R., \& Dubnikova, F. (2016). Synthesis and degradation of hexamethylene triperoxide diamine (HMTD). Propellants Explos. Pyrotech., 41, 334-350.

https://doi.org/10.1002/prep.201500151

[7] Schaefer, W.P., Fourkas, J.T., \& Tiemann, B.G. (1985). Structure of hexamethylene triperoxide diamine. J. Am. Chem. Soc., 107, 2461-2463.

https://doi.org/10.1021/ja00294a043

[8] Wierzbicki, A., Salter, E.A., Cioffi, E.A., \& Stevens, E.D. (2001). Density functional theory and x-ray investigations of $\mathrm{p}$ - and m-hexamethylene triperoxide diamine and its dialdehyde derivative. J. Phys. Chem. A, 105, 8763-8768.

https://doi.org/10.1021/jp0123841 
[9] Colizza, K., Porter, M., Smith, J.L., \& Oxley, J.C. (2015). Gas phase reactions of alcohols with hexamethylene triperoxide diamine (HMTD) under atmospheric pressure chemical ionization conditions. Rapid Commun. Mass Spectrom., 29(1), 74-80. https://doi.org/10.1002/rcm.7084

[10] Oxley, J.C., Smith, J.L., Chen, H., \& Cioffi, E. (2002). Decomposition of multi-peroxidic compounds: Part II. Hexamethylene triperoxide diamine (HMTD). Thermochim. Acta, $388,215-225$.

[11] Oxley, J., Zhang, J., Smith, J., \& Cioffi, E. (2000). Mass spectra of unlabeled and isotopically labeled hexamethylene triperoxide diamine (HMTD). Propellants Explos. Pyrotech., 25, 284-287.

https://doi.org/10.1002/1521-4087(200012)25:6<284::aid-prep284>3.0.co;2-x

[12] Oxley, J.C., Smith, J.L., Lou, L., \& Brady, J. ( 2009). Determining vapor pressures of diacetone diperoxide (DADP) and hexamethylene triperoxide diamine (HMTD). Propellants Explos. Pyrotech., 34(6), 539-543.

https://doi.org/10.1002/prep.200800073

[13] Gonsalves, M.D., McLennan, L., Slitt, A.L., Smith, J.L., \& Oxley, J.C. (2021). In vitro metabolism of HMTD and blood stability and toxicity of peroxide explosives (TATP and HMTD) in canines and humans. Xenobiotica, 51(4), 394403.

https://doi.org/10.1080/00498254.2021.1874563

[14] Aernecke, M.J., Mendum, T., Geurtsen, G., Ostrinskaya, A., \& Kunz, R.R. (2015). Vapor pressure of hexamethylene triperoxide diamine (HMTD) estimated using secondary electrospray ionization mass spectrometry. The Journal of Physical Chemistry A, 119(47), 11514-11522. https://doi.org/10.1021/acs.jpca.5b08929

[15] Bowden, P.R., Tappan, B.C., Manner, V.W., Preston, D.N., \& Scott, B.L. (2017). Characterization of diacetone diperoxide (DADP). AIP Conference Proceedings, 1793, 040010. https://doi.org/10.1063/1.4971504

[16] Stewart, J.J.P. (1989). Optimization of parameters for semi empirical methods I. $J$. Comput. Chem., 10, 209-220. https://doi.org/10.1002/jcc.540100208

[17] Stewart, J.J.P. (1989). Optimization of parameters for semi empirical methods II. $J$. Comput. Chem., 10, 221-264. https://doi.org/10.1002/jcc.540100209

[18] Leach, A.R. (1997). Molecular modeling. Essex: Longman.

[19] Kohn, W., \& Sham, L.J. (1965). Self-consistent equations including exchange and correlation effects. Phys. Rev., 140, 1133-1138.

https://doi.org/10.1103/PhysRev.140.A1133 
[20] Parr, R.G., \& Yang, W. (1989). Density functional theory of atoms and molecules. London: Oxford University Press.

[21] Becke, A.D. (1988). Density-functional exchange-energy approximation with correct asymptotic behavior. Phys. Rev. A, 38, 3098-3100.

https://doi.org/10.1103/PhysRevA.38.3098

[22] Vosko, S.H., Vilk, L., \& Nusair, M. (1980). Accurate spin-dependent electron liquid correlation energies for local spin density calculations: a critical analysis. Can. J. Phys., 58, 1200-1211. https://doi.org/10.1139/p80-159

[23] Lee, C., Yang, W., \& Parr, R.G. (1988). Development of the Colle-Salvetti correlation energy formula into a functional of the electron density. Phys. Rev. B, 37, 785-789. https://doi.org/10.1103/PhysRevB.37.785

[24] SPARTAN 06 (2006). Wavefunction Inc. Irvine CA, USA.

[25] Bach, R.D., \& Schlegel, H.B. (2020). Bond dissociation energy of peroxides revisited. Phys. Chem. A, 124(23), 4742-4751. https://doi.org/10.1021/acs.jpca.0c02859 